
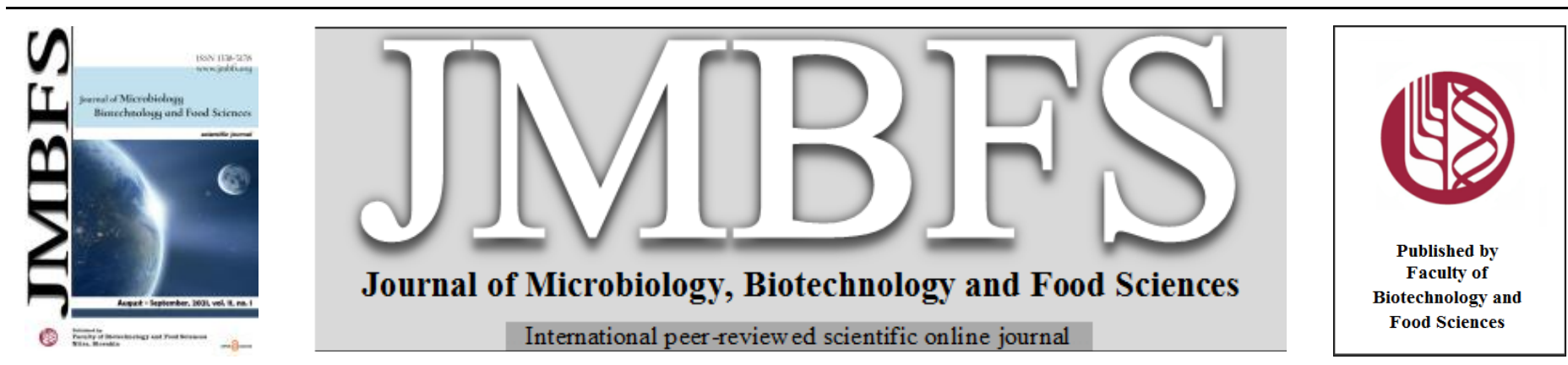

\title{
TWO NOVEL CLUSTERS OF NOCARDIOPSIS RECOVERED FROM HALOALKALINE ENVIRONMENT: POTENTIAL RESOURCE OF MULTI-ADVANTAGEOUS LIPASES
}

\author{
Moh. Abdel-Aziz M. Abdall *l
}

\section{Address(es):}

${ }^{1}$ National Research Centre (ID: 60014618), Pharmaceutical Industries Research Division, Chemistry of Natural and Microbial Products Department, Lab. no.181, 33 El Bohouth st., Dokki, Giza, Egypt, P.O. 12622. Tel: +20233371362, Ext. 1624. Fax: +2033370931; Mob.: +201007613420.

*Corresponding author: mmabdelaziz1976@yahoo.com

\section{ARTICLE INFO}

Received 2. 11. 2020

Revised 11. 2. 2021

Accepted 16. 2. 2021

Published 1. 8. 2021

Regular article OPEN $\partial_{\text {ACCESS }}$

\begin{abstract}
Wadi El Natrun district in the northwest of Cairo, Egypt, represents a highly stable unique ecology containing dual stress of salinity and alkalinity. Bioprospecting lipase producers in such an environment helps in finding enzymes of novel properties. Seven Nocardiopsis strains were recovered from Wadi El Natrun region, and their distribution within the phylogeny of the genus showed a particular pattern of two clusters descending from two evolutionary lineages. All strains produced highly alkaline lipase (optimum pH: 9- 11) in different amounts. The principal features of lipases from all strains, not only from the most potent one, were realized in a comparative profile to prospect more of their possible advantages in industrial biocatalysis. Most of the lipases were thermophilic; the optimum temperature was $50-55^{\circ} \mathrm{C}$ in lipases from five isolates. Activation energy of all lipases varied considerably between 5.52 and $13.58 \mathrm{Kcal} / \mathrm{mole}$. WN4L lipase exhibited the highest thermal stability (half-life time $=99 \mathrm{~min}$ at $70^{\circ} \mathrm{C}$ ). Interestingly, different lipases exhibited good stabilities in water-immiscible organic solvents which highlighted their suitability in the twopartitioning system applications. A general prospect about characteristic features of Wadi El Natrun lipases was realized; they share the multi-advantages of high alkalophilicity, tendency to be thermophilic, and readiness to work in acetone and water-immiscible solvents. Considering the extensive variation, each lipase appeared of a unique profile that enables to choose the most compatible one according to the specific circumstances of the interested industrial process. Moreover, a cocktail enzyme preparation of such lipases could be used as a multi-task lipase formula.
\end{abstract}

Keywords: Lipase; Nocardiopsis; Wadi El Natrun; Biocatalysis

\section{INTRODUCTION}

Lipases (EC 3.1.1.3) are a group of hydrolytic enzymes that catalyze the hydrolysis of the ester bond in lipids. They represent valuable players in many industrial sectors basing on unique characteristics (Bhosale et al., 2016). As such, lipases are found in the third order, after proteases and amylases, as the largest enzymes according to total sales volume (Hasan et al., 2006). Lipases have a great number of applications due to their functions as hydrolases or synthetases for many substrates like glycerides or non-glycerides, besides their versatile characteristics that fit different industries (Bhosale $\boldsymbol{e t}$ al., 2016; Schmid, and Verger, 1998). In the food industries, there were widespread uses in applications concerning flavors, dairy, baking, human milk fat substitutes, egg processing and edible oil production (Gandhi, 1997; Guerrand, 2017). Applications in organic chemicals processing included bioconversion in aqueous and organic media, resolution of racemic acids and alcohols, regioselective acylations and ester synthesis besides many other roles that include the activity of the enzyme towards non-glyceride substrates (Schmid, and Verger, 1998; Sharma et al., 2001). Their applications in the medical and pharmaceutical sectors included the usage of lipase with other components for the treatment of dyspepsias, gastrointestinal disturbances and cutaneous manifestations in some allergies (Mauvernay et al., 1970). Also, the lipase level in serum acts as a diagnostic indicator for acute pancreatitis and pancreatic injury (Lott and Lu, 1991). Moreover, Lipase could be used for the treatment of the malignant tumo basing on its role as an activator of tumor necrosis factor (Kato et al., 1989). Lipases are applied in detergent and laundry industries basing on their ability to remove fat stains (Awad, et al., 2015; Schmi, and Verger, 1998). In paper industries, lipases were applied in the treatment of lumber to be processed to lowgrade paper (Schmid, and d Verger, 1998). Lipases are used in leather industries for degreasing of animal skins and they have many advantages over other conventional alternatives and could afford substantial improvement in the production of hydrophobic (waterproof) leather (Hasan et al., 2006). In cosmetic industries, lipases are used as catalysts in the production of many health care esters like isopropyl palmitate and isopropyl myristate and they have achieved an advantageous role over other ordinary methods (Hasan et al., 2006). According to the transesterification property of some lipases, they played a promising role in the production of biodiesel from vegetable oils (Hasan et al., 2006). As such, patents concerning applications of lipase in biodiesel production are in rapid progress (Daiha et al., 2015). More roles of lipases in medical applications, biosensors and tea processing were reviewed by Hasan et al. (2006).

Up to $99.8 \%$ of the microbes are non-culturable and of those known culturable microbes, just a tiny fraction (2\%) was tested as enzyme sources (Hasan $\boldsymbol{e t}$ al., 2006). Thus, extensive survey studies to detect more lipase producers are strongly needed. The previous survey protocols about enzyme producers followed up the strategy of screening many producers and selecting the most potent one for further studies on enzyme characterization (Kulkarni and Gadre, 2002; Castro-Ochoa et al., 2005; Kanlayakrit and Boonpan, 2007). As such, the well-studied enzymes which used in many applications are those chosen in early survey steps basing on their quantitative superiority (produced in the highest amount comparing with others included during the survey) and of course they are not of qualitative superiority (best stabilities, unusual characteristics and specificity for definite industrial step). So, to avoid escaping enzymes of interesting characteristics and special values, surveys should be comprehensive enough to include preliminary investigations about stabilities and characteristics to present the knowledge base for many further studies to employ the most suitable for each definite industrial task.

Search for lipase producers in rare and scarcely studied environments is the way to find new enzymes of unusual characteristics and diverse applications. Haloalkaline habitat in Wadi El Natrun district in Egypt is one of the highly stable alkaline environment in the world (Horikoshi, 1999) and all lakes had $\mathrm{pH}$ values of 8.5-9.5 and salinity from 283 to $540 \mathrm{~g} / \mathrm{L}$ with very poor content in $\mathrm{Ca}^{+2}$ and $\mathrm{Mg}^{+2}$ and so appear to be unique among saline lakes (Taher, 1999). Because such an environment contained combined double extremities of salt and alkalinity, the resident microbes were considered promising candidates for novel unique macromolecules. As such, the current study aimed to bio-prospect lipase 
producers in halo-alkaline habitat in the Wadi El Natrun district and adopted the comprehensive survey protocol that reports the productivities beside the characteristics and stabilities for lipases from all producers to depict the versatility profile and show their prospected applications.

\section{MATERIALS AND METHODS}

\section{Chemicals}

Organic solvents (methanol, ethanol, isopropanol, acetone, ethyl acetate, chloroform and cyclohexane) were purchased from Fisher Scientific International Inc., Pennsylvania, USA. All other chemicals were AR grade from Merck KGaA Co., Germany. Nylon syringe filters $(0.45 \mu \mathrm{m})$ were delivered from Bona-Agela, Tianjin, China.

\section{Isolation}

The strains of the current study were isolated from the coastline of Al-Beida Lake in the Wadi Natrun district in Egypt. Isolation was done on agar plates of a starch-casein medium (Atlas, 1997) with $5 \% \mathrm{NaCl}$ and $\mathrm{pH}$ adjusted at 8.5 before sterilization. The plates were incubated for five days at $28 \pm 2^{\circ} \mathrm{C}$. Many colonies had appeared and those showed apparent repeated existence (more than $10^{3}$ c.f.u. per gram soil) were spread onto the surface of separate agar plates of the same isolation medium. Touch of the terminal colonial growth were transferred to slants of the same medium and preserved as frozen spore suspension in glycerol solution at $-80^{\circ} \mathrm{C}$.

\section{Molecular characterization basing on sequencing 16s rRNA}

The work for extraction, amplification and sequencing 16S rRNA was conducted by Technical Services Co. (Giza, Egypt). It based on using the different kits as described in inserts attached to the kits. The extraction of genetic material was done using the Gene Jet genomic DNA purification Kit (Thermo K0721) Amplification has been done by Maxima Hot Start PCR Master Mix (Thermo K1051). Purification of PCR product was attained by Gene JETTM PCR Purification Kit (Thermo K0701). Sequencing the PCR product was conducted using ABI 3730xl DNA sequencer.

\section{Molecular analyses}

Sequences of Wadi Natrun isolates and those from NCBI for related sequences were accessed using BioEdit software (Hall, 1999). Multiple sequence alignment was conducted using MEGA software version 6 (Tamura et al., 2013). The evolutionary history was inferred from Tamura-Nei model (Tamura and Nei, 1993). The bootstrap value was calculated by MEGA 6 and implemented in the phylogenetic tree for estimating the standard error of the interior branch and the deviation of the branch length from 0 (Dopazo, 1994). In bootstrap calculations, the reliability of a given branch pattern is ascertained by examining the frequency of its occurrence in a large number of trees, each based on 500 re-sampled datasets.

\section{Fermentation}

Fermentations were carried out in 250-ml Erlenmeyer flasks containing $50 \mathrm{ml}$ of starch-casein broth medium (Atlas, 1997) modified by reducing the amount of starch to $2 \mathrm{~g} / \mathrm{l}$, the addition of $5 \%$ sodium chloride and rising $\mathrm{pH}$ to 8.5 before autoclaving. Olive oil was separately autoclaved and added to the sterile flasks of starch-casein medium $(0.5 \mathrm{ml} /$ flask $)$. Each flask was then inoculated with $1 \mathrm{~m}$ thawed spore suspension containing about $5.5 \times 10^{8}$ c.f.u. $/ \mathrm{ml}$. The flasks were then incubated at $28 \pm 2^{\circ} \mathrm{C}$ and $150 \mathrm{rpm}$ for 5 days. Pellets of microbial growth were separated by cooling centrifugation (10000 rpm for 15 minutes) and the pure filtrate was used as the source of extracellular lipase enzyme.

\section{Buffer preparation}

Different buffers have been used to cover a wide range of $\mathrm{pH}$ values. They are used in single- or double-strength levels. Double-strength buffers (at a concentration of $100 \mathrm{mM}$ ) were used to be mixed with the same volume of enzyme solution to study $\mathrm{pH}$ stability whereas single-strength preparations were used in the enzyme reaction mixture at various $\mathrm{pH}$ values. Citrate phosphate buffer was used to cover the $\mathrm{pH}$ range from 3 to 7 . For $\mathrm{pH}$ range from 7.5 to 9 , Tris- $\mathrm{HCl}$ buffer was used. Carbonate/bicarbonate buffer was used to cover the $\mathrm{pH}$ range from 9.5 to 10.5 while disodium hydrogen phosphate/sodium hydroxide buffer was used to cover the $\mathrm{pH}$ range from 11 to 12 . Potassium chloride/sodium hydroxide buffer was used to cover the $\mathrm{pH}$ range from 12.5 to 13 .

\section{Lipase activity}

The lipolytic activity was determined using p-nitrophenyl palmitate (p-NPP) as a substrate and measuring the concentration of liberated $\mathrm{p}$-nitrophenol (p-NP) by the spectrophotometric method as described by Aziz et al. (2020). Briefly, a solution of p-NPP $(10 \mathrm{mM})$ in isopropanol was prepared and a volume of $20 \mu \mathrm{l}$ of this solution was transferred to a test tube containing $300 \mu \mathrm{l}$ of single-strength buffer solution (tris- $\mathrm{HCl}$ buffer of $\mathrm{pH} 8$ was used in initial screening investigations and specific buffer of optimal activity of each enzyme was then used after identifying optimum $\mathrm{pH}$ of activity). To this buffered substrate suspension, a sample of the enzyme $(30 \mu \mathrm{l})$ was added and the test tube was then incubated in a water bath at $37 \pm 2{ }^{\circ} \mathrm{C}$ (or at certain temperatures assigned in some experiments) for 30 minutes under continuous shaking $(150 \mathrm{rpm})$. Excess sodium carbonate solution $(3 \mathrm{ml}, 0.1 \mathrm{M})$ was added, to ensure sufficient alkaline medium, and then the contents of each tube were filtered using a nylon syringe filter $(0.45$ $\mu$ ) before measuring the absorbance at $400 \mathrm{~nm}$ by Jasco UV-VIS spectrophotometer. For each sample, a blank was prepared typically as the sample without adding the enzyme. Readings of standard concentrations of $\mathrm{p}-\mathrm{NP}$ in $\mathrm{Na}_{2} \mathrm{CO}_{3}$ solution $(0.1 \mathrm{M})$ were used to get the product concentrations in samples. The coefficient of extinction $(\varepsilon)$ of p-NP under the conditions described was determined as $21 \mathrm{mM}^{-1} . \mathrm{cm}^{-1}$. One enzyme unite was the amount of enzyme liberating $1 \mu$ mole of p-NP per minute under specified conditions. Samples were prepared in duplicates and the average was the result representing the sample.

\section{Stability at different $\mathrm{pH}$ values}

For studying the stability against buffered $\mathrm{pH}, 0.5 \mathrm{ml}$ of culture filtrate containing the enzyme was mixed with an equal volume of a double-strength buffer of the assigned $\mathrm{pH}$ value at room temperature and tested for relative residual activity (percent of residual activity to the initial activity) after one and two hours. The sample tested immediately after mixing enzyme and buffer was considered as $100 \%$ relative enzyme activity.

\section{Stability at different temperatures}

Enzyme stability at different temperatures was assayed in standardized buffered conditions by mixing $0.5 \mathrm{ml}$ enzyme solution with an equal volume of doublestrength phosphate buffer $(\mathrm{pH} 7)$ and incubating the mixture at assigned temperature to be tested for the residual enzyme activity at different time intervals. The control enzyme activity was the activity at the start of incubation (Pera et al., 2006). Relative activity (in percentage) is the activity of the sample relative to the control activity.

\section{Stability against different metal ions}

Solution $(100 \mathrm{mM})$ of each of the metal ions $\mathrm{Na}^{+}, \mathrm{K}^{+}, \mathrm{Ca}^{+2}, \mathrm{Mg}^{+2}, \mathrm{Mn}^{+2}, \mathrm{Co}^{+2}$ $\mathrm{Zn}^{+2}, \mathrm{Fe}^{+3}$ and $\mathrm{Cu}^{+2}$ was prepared from the following salts $\mathrm{NaCl}, \mathrm{KCl}, \mathrm{CaCl}_{2}$, $\mathrm{MgCl}_{2} .6 \mathrm{H}_{2} \mathrm{O}, \mathrm{MnCl}_{2} .4 \mathrm{H}_{2} \mathrm{O}, \mathrm{Co}\left(\mathrm{NO}_{3}\right)_{2} .6 \mathrm{H}_{2} \mathrm{O}, \mathrm{ZnSO}_{4} .7 \mathrm{H}_{2} \mathrm{O}, \mathrm{FeCl}_{3}, \mathrm{CuSO}_{4} .5 \mathrm{H}_{2} \mathrm{O}$ respectively. Then, $0.5 \mathrm{ml}$ of the enzyme solution was incubated with $0.5 \mathrm{ml}$ of the tested metal solution at room temperature for an hour (Chauhan and Garlapati, 2013) after which the relative residual activity of the enzyme was determined. In the same manner, the control sample was prepared using distilled water instead of a metal solution.

\section{Solvent stability}

Lipase-containing culture filtrate was diluted in a 10-ml screw-capped glass tube in the ratio of 1:1 with each of the tested organic solvents (methanol, ethanol, isopropanol, acetone, ethyl acetate, chloroform and cyclohexane) and incubated for an hour (Pera et al., 2006) at room temperature $\left(25 \pm 2{ }^{\circ} \mathrm{C}\right)$ under contentious shaking $(150 \mathrm{rpm})$ and then the mixture of solvent-enzyme was assayed for the relative enzyme activity. The control was the enzyme sample treated with distilled water instead of solvent. In the case of water-immiscible solvents (ethyl acetate, chloroform and cyclohexane), the two phases (solvent and aqueous enzyme solution) were allowed to separate before sampling from the aqueous phase, and the control sample was that of the non-treated enzyme.

\section{Thermodynamic properties}

\section{The activation energy $(\mathrm{Ea})$}

The activation energy (Ea) represents the difference in energy between the reactants and the transition state (or activated complex) of a given reaction. It was determined according to Kumari et al. (2008) by plotting the natural logarithm of the relative enzyme activity at different temperatures against the reciprocal of temperature degree in Kelvin. Then $\mathrm{Ea}$ in $\mathrm{kJ} / \mathrm{mole}$ was calculated from the equation:

$\mathrm{Ea}=-$ slope $* 8.314 / 1000$

\section{Parameters of thermal stability}

The heated buffered enzyme (phosphate buffer, $\mathrm{pH} 7$ ) at different temperatures was tested for residual activity at regular intervals. The first order deactivation 
rate constants were calculated as described by Gohel and Naseby (2007) using the following relation:

$\ln \left(\mathrm{E} / \mathrm{E}_{0}\right)=-\mathrm{K}_{\mathrm{d}} \mathrm{t}$

Where $E$ is the residual activity; $E_{0}$ is the activity of non-heated enzyme; $K_{d}$ is the first order deactivation rate constant in $\min ^{-1} ; \mathrm{t}$ is the time in min

The half-life time of an enzyme is the time that it takes for the activity to reduce to half of the original activity. It was determined according to Ortega $\boldsymbol{e t} \boldsymbol{a l}$. (2004) from the relation:

$\mathrm{t}_{1 / 2}=\ln 2 / \mathrm{k}_{\mathrm{d}}$

Where $\mathrm{t}_{1 / 2}$ is the half-life time (min.)

\section{RESULTS AND DISCUSSION}

Isolation of microbial strains and molecular characterization

The Wadi El Natrun district is located about $90 \mathrm{~km}$ northwest of Cairo, Egypt, and represents an elongated depression of 23 meters below sea-level (Taher, 1999). Al-Beida Lake, one of the soda salt marshes in the Wadi El Natrun district, was undertaken in isolation course to investigate its composition of Actinobacteria using starch-casein medium modified with $5 \% \mathrm{NaCl}$ and $\mathrm{pH} 8.5$. The samples collected at latitude and longitude of $30^{\circ} 26^{\prime} 20^{\prime \prime} \mathrm{N}$ and $30^{\circ} 14^{\prime} 44.0^{\prime \prime} \mathrm{E}$ showed repeated occurrence (basing on apparent cultural characteristics) of eight different strains (their colony count exceeded 103 c.f.u./gm) after five days of incubation at $28^{\circ} \mathrm{C}$. The strains were considered true residents in soda salt marsh and were thus further streaked on the surface of agar plates before being transferred to slants of the same isolation medium. Molecular characterization of the eight strains basing on 16S rRNA gene sequencing showed that seven of them belonged to the genus Nocardiopsis and one was a member of the genus Streptomyces. The strains of Nocardiopsis which colonized the halo-alkaline environment at a high incidence rate with evidenced molecular diversity were thus focused in the current study. The seven Nocardiopsis strains isolated were assigned as NRC/WN1, NRC/WN2, NRC/WN3, NRC/WN4, NRC/WN5, NRC/WN6 and NRC/WN7 and their sequences of 16S rRNA gene were deposited in NCBI GenBank under the accession numbers MG970554, MG970555, MG970556, MG970557, MG970558, MG970559 and MG970560 respectively. This the first time to report about the occurrence of Nocardiopsis in halo-alkaline marshes of Wadi El Natrun in Egypt although it is previously isolated from different sites in Egypt (Sabry et al., 2004; Hozzein et al., 2004 El-Naggar, 2014). As reported by Hamedi et al. (2013), the genus Nocardiopsis is the largest abundant halophilic actinomycete. They have high adaptation capabilities and could so spread over the entire world in different habitats and hosts with interesting abilities to produce degrading enzymes and antimicrobial agents (Bennur et al., 2015). To sketch out the relation of the current Nocardiopsis strain to other known species of the genus, phylogenetic analysis, basing on the 16S rRNA gene sequence, was conducted. As indicated in Fig. 1, the phylogenetic tree showed that the current strains were arranged in a special pattern within the phylogeny of the genus. They are grouped in two clusters that are distinguishable from other neighbors of known Nocardiopsis species. The two clusters evolved from two evolutionary lineages, the first lineage is strongly related to the $N$. nikkonensis strain (includes strains NRC/WN1, NRC/WN2, NRC/WN3, NRC/WN4 and NRC/WN7) and the second is related to $N$ flavescens (includes the strains NRC/WN5 and NRC/WN6). Also, Fig. 1 showed clearly that the current strains were genetically distant to other strains recovered previously in Egypt or those reported by Hamedi et al. (2013) as validly described halophilic/halotolerant species, which may propose the assumption of belonging the current clusters of Nocardiopsis strains to, at least, two novel species. It was also thought that phylogenetic topology within the first cluster $(N$. nikkonensis cluster) has created to ancestral taxon under the stress of salt and alkalinity in Al-Beida lake. Additionally, Fig. 1 showed that halophilic or halotolerant species of Nocardiopsis are scattered along the phylogenetic tree without restriction to certain species which reflected the frequent readiness of the genus to adopt ecological conditions and pointed out to the rich molecular readiness of the genus Nocardiopsis for biodiversity.

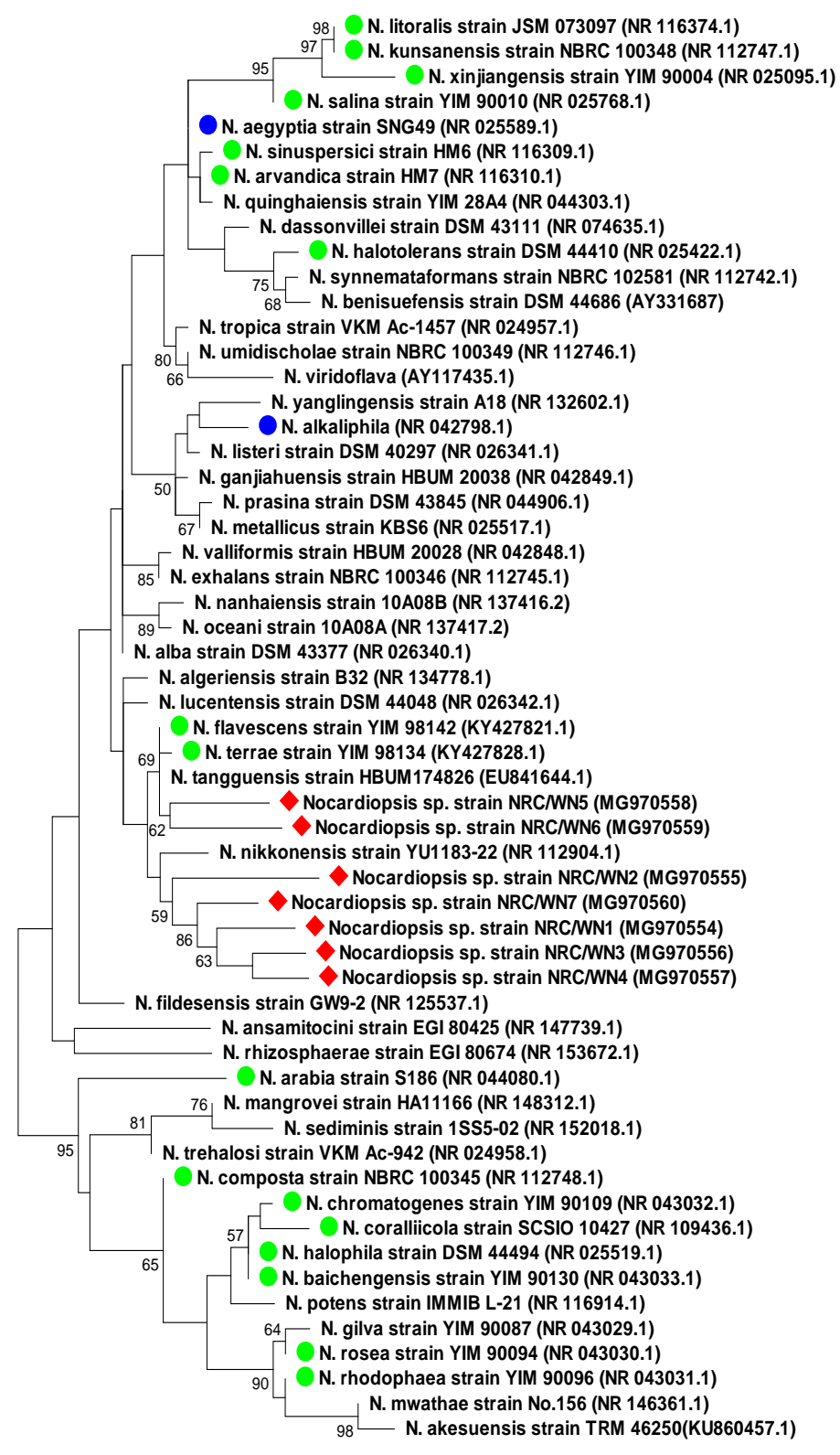

$\lcm{0.005}$

Figure 1 Molecular phylogenetic analysis of Wadi El Natrun isolates with representatives of other known species of the genus Nocardiopsis basing on 16S rRNA gene sequence. Phylogenetic tree was constructed by MaximumLikelihood method using the sequences in NCBI gene bank of the accession numbers that have been indicated between parentheses. Bootstrap values were calculated as percentages from 500 replications and only values above or equal to $50 \%$ were shown at nodes. The tree is drawn to scale with branch lengths measured in the number of substitutions per site. Legend: Strains isolated through the current study from Wadi El Natrun; • Species reported by Hamedi $\boldsymbol{e}$ al. (2013) as validly described halophilic or halotolerant species; - Species reported by Bennur et al. (2015) as previously isolated from Egypt.

Table 1 Different $\mathrm{pH}$ ranges and optima of lipases produced by Nocardiopsis strains of Wadi El Natrun

\begin{tabular}{lllll}
\hline Lipase & $\begin{array}{l}\text { Source } \\
\text { (strain) }\end{array}$ & pH range* & Optimum $\mathrm{pH}$ & $\begin{array}{l}\text { Productivity** } \\
\left(10^{-3} \mathrm{IU}^{*} \mathrm{ml}^{-1}\right)\end{array}$ \\
\hline WN1L & NRC/WN1 & $3-13$ & 9.5 & 28.8 \\
\hline WN2L & NRC/WN2 & $3-13$ & 9.5 & 12.7 \\
\hline WN3L & NRC/WN3 & $5.5-13$ & 10 & 17.8 \\
\hline WN4L & NRC/WN4 & $3.5-13$ & 11 & 58.8 \\
\hline WN5L & NRC/WN5 & $3.5-13$ & 11 & 173.8 \\
\hline WN6L & NRC/WN6 & $3-13$ & 9 & 69.2 \\
\hline WN7L & NRC/WN7 & $4-13$ & 10.5 & 38.3 \\
\hline
\end{tabular}

* The $\mathrm{pH}$ range that exhibited not less than $1 \%$ of the activity at optimum $\mathrm{pH}$

** Productivity was determined in modified starch-casein medium under nonoptimized cultural and nutritional conditions that were indicated in materials and methods. 


\section{Lipolytic activity of the isolated strains}

Preliminary testing of lipolytic activity within Nocardiopsis isolates using enzyme assay at selected $\mathrm{pH}$ of 8 (tris buffer, $50 \mathrm{mM}$ ) showed that all strains produced lipases (100\% incidence rate in randomly isolated strains), and these enzymes will be referred to as WN1L, WN2L, WN3L, WN4L, WN5L, WN6L and WN7L for the different producer strains as illustrated in Table 1. For each of the enzymes, lipolytic activity was assayed at different $\mathrm{pH}$ values (using buffers ranged from $\mathrm{pH} 3$ to 13 ) and it was found that different lipases from Nocardiopsis isolates showed different $\mathrm{pH}$ ranges and optima as indicated in Table 1 . The results showed that all lipases can work over a wide range of $\mathrm{pH}$ with optima at high alkaline values (9-11) which reflected adaptability of produced lipases to ecologies of highly alkalinity. It is noticeable that optimum pHs were higher than that of many other alkaline lipases reviewed by Salihu and Alam (2015). Although many investigations reported the ability of Nocardiopsi spp. to produce various enzymes (Bennur et al., 2014; Chakraborty et al. 2015; Gandhimathi et al., 2009; Kumar et al., 2012; Meena et al., 2013), there was no clear evidence for the production of alkaline lipase. Mitsuiki et al. (2002) concluded wrongly the ability of Nocardiopsis $s p$. to produce alkaline lipase from its ability to grow on solid alkaline medium containing tween 80 , and of course the ability of lipase to show activity in an alkaline medium does not necessarily mean that its activity in such medium is the optimal. It was so claimed that the current study is the first clear elucidation for the existence of alkaline lipases in Nocardiopsis strains. The productivity of all strains was then determined, using enzyme assays adjusted at specific optimum $\mathrm{pH}$ of each enzyme, and it has been shown in Table 1. A great variation was observed concerning the productivity of lipases. From the lowest lipase producer (strain NRC/WN2) to the highest (strain NRC/WN5) the increase in productivity was about 13 fold.
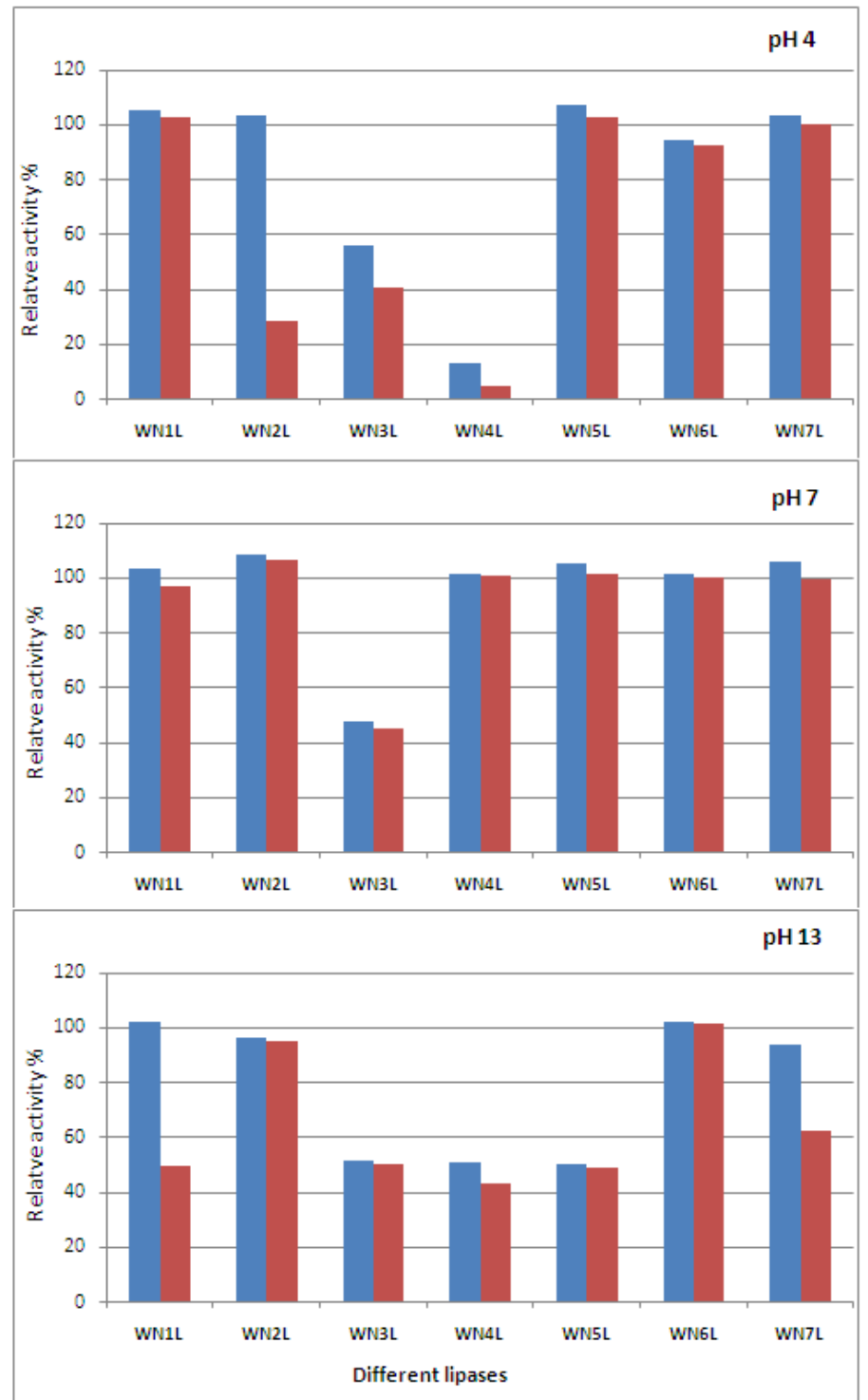

Figure 2 Stability of lipases from different Nocardiopsis strains of Wadi E Natrun in buffers of different $\mathrm{pH}$ values; $\mathrm{pH} 4, \mathrm{pH} 7$ and $\mathrm{pH} 13$. Blue and red columns represent the relative activity percent after one and two hours respectively.

\section{Stability of lipases from different Nocardiopsis spp. against pH}

Stability of different lipases from Wadi El Natrun isolates against $\mathrm{pH}$ was studied and compared after incubation in buffers of $\mathrm{pH} \mathrm{4,7}$ and 13 at room temperature for one and two hours. As indicated in Fig. 2, at acidic $\mathrm{pH}$, lipases from many strains (WN1L, WN5L, WN6L and WN7L) showed good stability (around 100\% activity) even after two hours in acidic buffered $\mathrm{pH} 4$. On the other side, lipases from strains $\mathrm{NRC} / \mathrm{WN} 3$ and $\mathrm{NRC} / \mathrm{WN} 4$ were very sensitive to acidic $\mathrm{pH}$ where activity dropped to $56 \%$ and $13.1 \%$ after one hour then to $40.6 \%$ and $4.7 \%$ after two hours respectively. Although Salihu and Alam (2015) reviewed the characteristic features of the $\mathrm{pH}$ stability of many alkaline lipases, little was known about stability in $\mathrm{pH}$ as low as 4 . At $\mathrm{pH} \mathrm{7,} \mathrm{there} \mathrm{was} \mathrm{observable} \mathrm{high}$ stability of nearly all lipases which showed activity around $100 \%$ even after two hours of incubation. In extremely alkaline $\mathrm{pH}$ of 13, lipases from Wadi El Natrun strains were able to show different degrees of stability. WN2L and WN6L showed persistent stability and could retain more than $95 \%$ of the initial activity with prolonged incubation in the buffer for two hours. Reviewing the $\mathrm{pH}$ stabilities of 13 different alkaline lipases reported by many investigators (Bora and Bora, 2012; Hu et al., 2018; Salihu and Alam, 2015) showed that stability at an extremely high $\mathrm{pH}$ of 13 was a special privilege of lipases of the current Wadi El Natrun Nocardiopsis strains and has not ever been reported. WN1L and WN7L exhibited good stabilities for one-hour incubation and retained relative activity of $62.6 \%$ and $49.8 \%$ respectively after two hours. Other lipases (WN3L, WN4L and WN5L) were less stable and showed a reduction in activity after one hour.

\section{Effect of temperature on activity and stability of different lipases}

The results depicted in Fig. 3 showed that the Nocardiopsis strains of Wadi El Natrun introduced a panel of lipases of different optimum temperatures of activity. In ascending order, the optimum temperatures were 35,40 and $50^{\circ} \mathrm{C}$ for WN7L, WN1L and WN4L respectively. The temperature of $55^{\circ} \mathrm{C}$ was the most common where it was the optimum for lipases WN2L, WN3L, WN5L and WN6L which reflected the general tendency of lipases in Nocardiopsis of Wadi El Natrun to be thermo-alkaline enzymes.

As biocatalysts, the lipases of the current Nocardiopsis strains could decrease the activation energy of lipid hydrolysis reaction and according to the data presented in Table 2, there was great variation in activation energies of the different Wadi El Natrun lipases. A linear decrease in activation energy results in an exponential increase in reaction rate (Pogaku et al., 2012). Interestingly WN5L could reduce the activation energy (Ea) to $5.5 \mathrm{Kcal} / \mathrm{mole}$ which is less than half of that of WN1L $(13.58 \mathrm{Kcal} / \mathrm{mole})$ and so indicated the highest reactivity of WN5L over all other lipases. Stability of different lipases in response to heating up to $70^{\circ} \mathrm{C}$ for different times was depicted in Fig. 4 which showed that WN4L followed by WN2L were the most stable and could retain more than $60 \%$ of the original activities after incubation for 45 minutes. Some other lipases (WN1L, WN7L and WN5L) showed very low stabilities while others like WN3L and WN6L were moderately stable. Thermodynamic parameters for irreversible heat inactivation of the different lipases were expressed by dissociation rate constant and the halflife time of enzyme as indicated in Table 2. The lower dissociation rate constant is the higher half-life time. In general, the profile of temperature effect on enzyme activity and stability for Wadi El Natrun lipases showed no specific features of Wadi El Natrun lipases comparing with lipases from different sources perhaps because the Wadi El Natrun environment has temperature levels ranged from 14.2 to $29.5{ }^{\circ} \mathrm{C}$ (Taher, 1999) which are similar to that in conventional habitats.

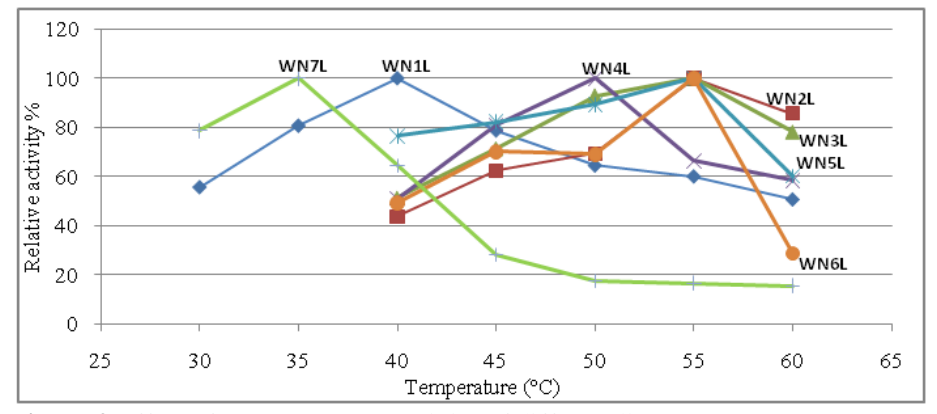

Figure 3 Effect of temperature on activity of different lipases 
Table 2 Thermodynamic Parameters of different lipases of Wadi El Natrun great activation by all other tested metal ions. The versatility of different lipases Nocardiopsis strains

\begin{tabular}{lccc} 
Lipase & $\begin{array}{c}\text { Activation energy (Ea) } \\
\text { Kcal/mole }\end{array}$ & $\begin{array}{c}\text { Dissociation rate } \\
\text { constant*, } \\
\mathrm{k}_{\mathrm{d}}\left(\mathrm{min}^{-1}\right)\end{array}$ & $\begin{array}{c}\mathrm{t}_{1 / 2}{ }^{*} \\
(\mathrm{~min} .)\end{array}$ \\
\hline WN1L & 13.58 & 0.2505 & 2.8 \\
\hline WN2L & 9.31 & 0.0092 & 75.3 \\
\hline WN3L & 8.24 & 0.0159 & 43.6 \\
\hline WN4L & 11.25 & 0.007 & 99.0 \\
\hline WN5L & 5.52 & 0.1152 & 6.0 \\
\hline WN6L & 7.84 & 0.0581 & 11.9 \\
\hline WN7L & 8.88 & 0.1056 & 6.6 \\
\hline
\end{tabular}
in response towards different ions reflected the extent of variation in lipases produced in the same environment by very closely related strains. Elucidating the stability profile of each lipase offers the opportunity to choose the one which is the most compatible with the specific circumstances of each industrial process.

${ }^{*}$ Calculated at $70{ }^{\circ} \mathrm{C}$
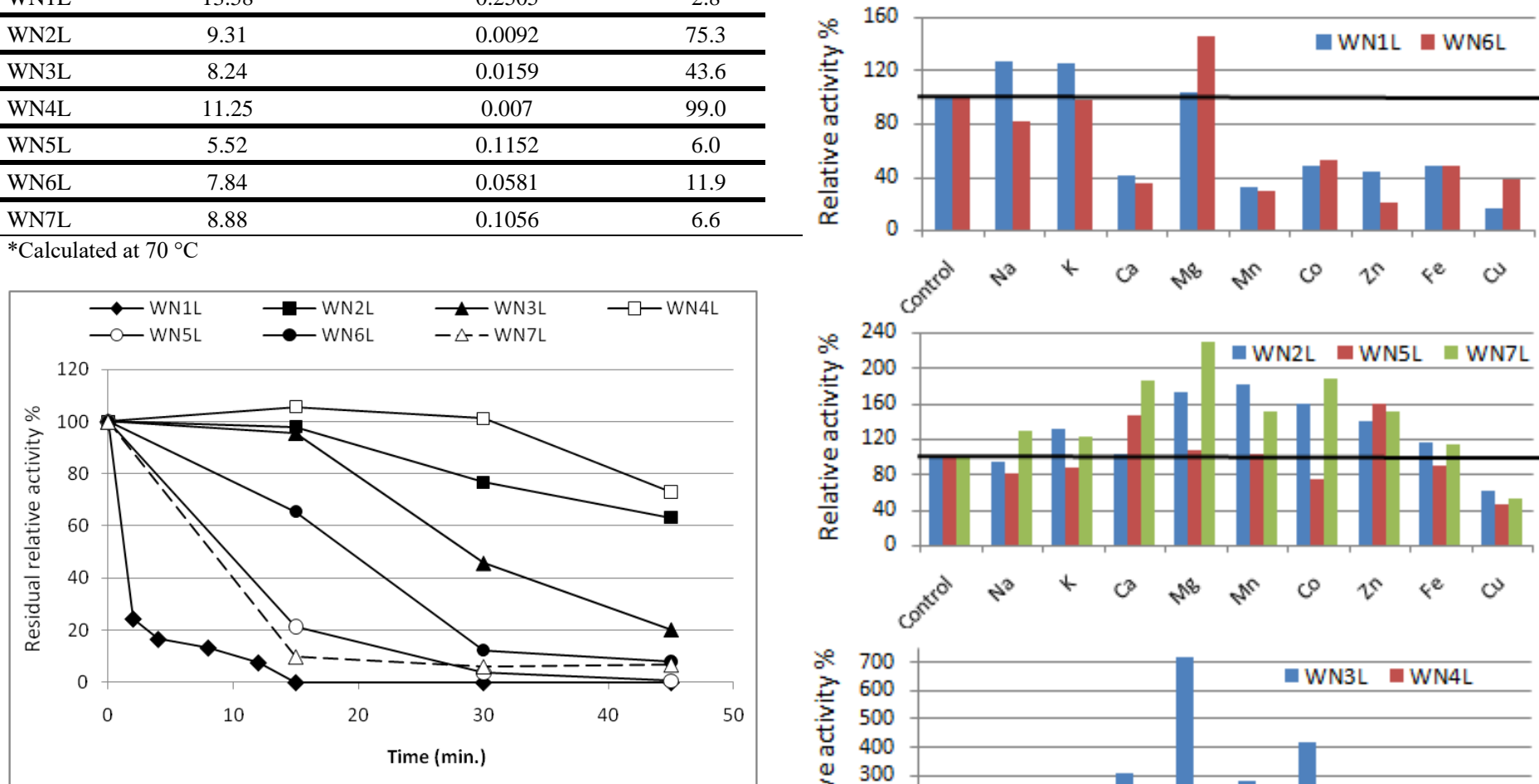

Figure 4 Relative residual activities of different lipases after incubation at $70^{\circ} \mathrm{C}$ for different times.

\section{Stability of different lipases against different metal ions}

For studying the action of metal ions on different lipases, each enzyme was incubated with metal ions separately for an hour at room temperature and then the residual enzyme activity was expressed as relative activity percent. The results in Fig. 5 showed that each lipase has a distinct profile of response towards different ions. It was noticeable that the response of lipases towards $\mathrm{Na}^{+}$ions ranged from good stability (in case of WN2L, WN5L and WN6L, where relative activity exceeded $80 \%$ ) to different degrees of activation in the other lipases namely WN1L, WN3L, WN4 and WN7 where relative activity were 126.6, $163.3,196.5$ and $129.2 \%$ respectively. A greatly similar was the profile in the case of another monovalent ion $\mathrm{K}^{+}$. Many ions appeared repeatedly in the literatures as activators of lipases (Hasan et al., 2009), however, $\mathrm{Na}^{+}$ions were scarcely documented as lipase activators. It was thought that activation of most of the current lipases in response to $\mathrm{Na}^{+}$is a good feature for adaptation of the producer strains to a salty environment. The highest activation by $\mathrm{Na}^{+}$ions took place in lipases produced by Nocardiopsis strains NRC/WN3 and NRC/WN4 which appeared in the phylogenetic tree at the end of the evolutionary lineage of the second cluster. It was speculated previously in the current study that all members of the second cluster descended from a common ancestor under the effect of salt soda environment, so strains of NRC/WN3 and NRC/WN4 would be the most adapted and their ability to employ $\mathrm{Na}^{+}$ions in a beneficial role represents a reasonable feature for the previous speculation. Magnesium ion worked as a common activator for all lipases and it potentiated activity to more than 7 times in WN3L. This is in agreement with many types of lipases from different organisms (Hasan et al., 2009; Lajis, 2018). Moreover, Bhosale et al. (2016) found that $\mathrm{MgSO}_{4}$ in a concentration of $150 \mathrm{mM}$ has potentiated a $349.94 \%$ increase in the activity of thermo-alkaline lipase from Bacillus sonorensis 4R. Calcium and manganese ions showed different degrees of activation in all lipases with the exception in the case of WN1L and WN6L where a remarkable loss in the activity to less than $50 \%$ was realized. Inactivation of lipases by $\mathrm{Ca}^{+2}$ and $\mathrm{Mn}^{+2}$ was reported in lipases produced by strains of Acinetobacter and Staphylococcus aureus respectively (Hasan et al., 2009). Heavy metals $\left(\mathrm{Fe}^{+3}\right.$ and $\left.\mathrm{Zn}^{+2}\right)$ were of inhibitory action to some of the current lipases which is a common effect in previously described lipases (Chakraborty and Raj 2008; Hasan et al. 2009; Kambourova et al. 2003; Sharma et al. 2001) however, they showed surprising activation to WN2L, WN3L and WN7L. Nearly all of the current lipases were sensitive to cupric ions which caused an obvious inactivation. Inactivation of lipases by $\mathrm{Cu}^{+2}$ ions was reported in elsewhere (Sharma et al., 2001; Kambourova et al., 2003; Chakraborty and Raj, 2008; Hasan et al., 2009). Out of all studied lipases, WN3L showed a unique response where it showed no loss in activity with cupric ions and showed
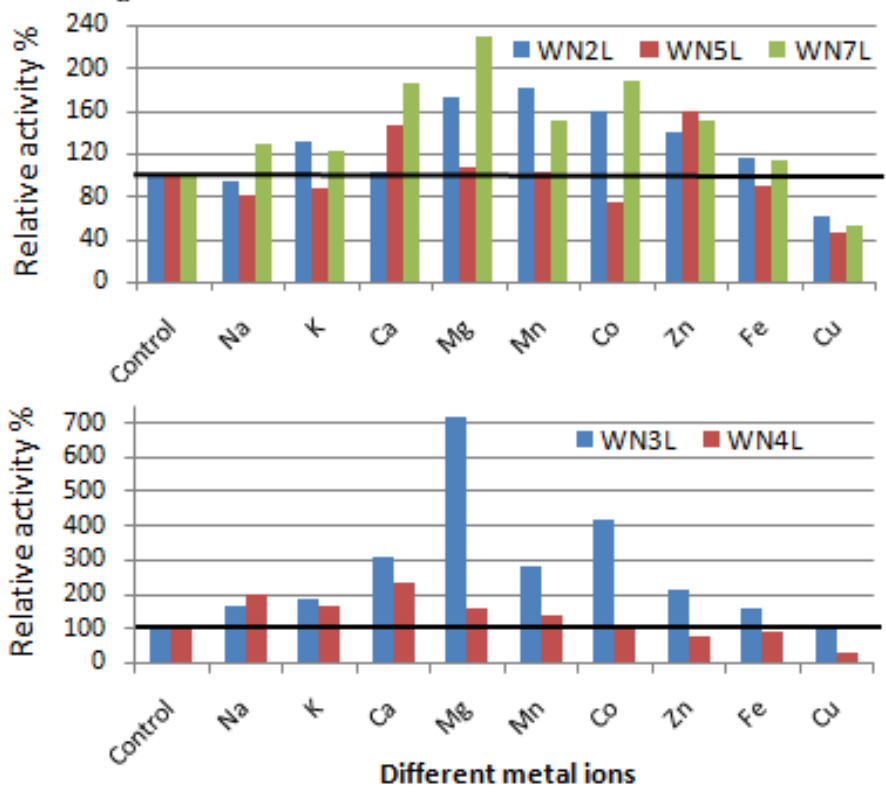

Figure 5 Effect of metal ions on different lipases

\section{Solvent stability of different lipases}

The results depicted in Fig. 6 showed that Wadi El Natrun lipases exhibited considerable stabilities in many organic solvents. The stability of each lipase in the organic solvent depends on the polarity of the solvent (Sangeetha et al. 2011). To get a general prospect from the Fig. 6, the response of different Wadi El Natrun lipases against the action of organic solvents would be distinguished into the four categories: 1) stimulation in the activity (great increase in relative activity than $100 \%$ ); 2 ) high stability (relative activity exceeds $80 \%$ to normal activity); 3) moderate stability (30 - 80\% relative activity); and 4) low stability (less than $30 \%$ relative activity). Stimulation in enzyme activity by organic solvents was observed in the case of WN1L (by acetone, ethyl acetate and chloroform), WN4L (by isopropanol, acetone and ethyl acetate), WN3L (by isopropanol and acetone) and WN2L (by acetone). Some similarities in responses of WN4L and WN3L may be attributed to the relatedness between them (on molecular bases of $16 \mathrm{~S}$ rRNA) which could be inferred from the phylogenetic tree (Fig. 1). The previous study of Cao et al. (2012) reported the stimulation in lipase activity by isopropanol and acetone in a concentration of $25 \% \mathrm{v} / \mathrm{v}$, whereas it is recorded here in WN3L and WN4L in an enzyme/solvent dilution of 1:1 which equivalent to $50 \%$ solvent. Additionally, surprising responses against water-immiscible solvents (ethyl acetate, chloroform and cyclohexane) were observed; the responses were in the range of high to moderate stability in most cases and the range of increased activity in other cases. Against chloroform, WN1L showed enhanced activity (more than $115 \%$ relative activity) whereas WN2L, WN3L, WN4L and WN7L showed high stability. However, WN5L and WN6L showed comparable relative activities near $70 \%$ with chloroform. In the case of the non-polar solvent cyclohexane, WN1L and WN6L were of high stability whereas other lipases were of moderate stability. Most organic chemical synthesis in the field of pharmaceuticals, cosmetics and food takes place in a water-free medium to favor the enzymatic reaction in the direction of esterification and transesterification (Sharma et al., 2001) and in some cases to hydrolyze water-insoluble esters during resolution of racemic mixtures (Hasan $\boldsymbol{e t}$ al., 2006). Therefore, the common characteristic tendency of Wadi El Natrun lipases to be of promising activity in presence of water-immiscible solvents reflected their suspected extraordinary value in the two-partitioning system 
applications, the future of many industries of biopolymers, transesterification reactions and biodiesel production (Sangeetha et al., 2011). On the other side, the response in the case of methanol and ethanol was not the same as in the other organic solvents; with few exceptions, mostly all Wadi El Natrun lipases were of low stability against one or both of methanol and ethanol.

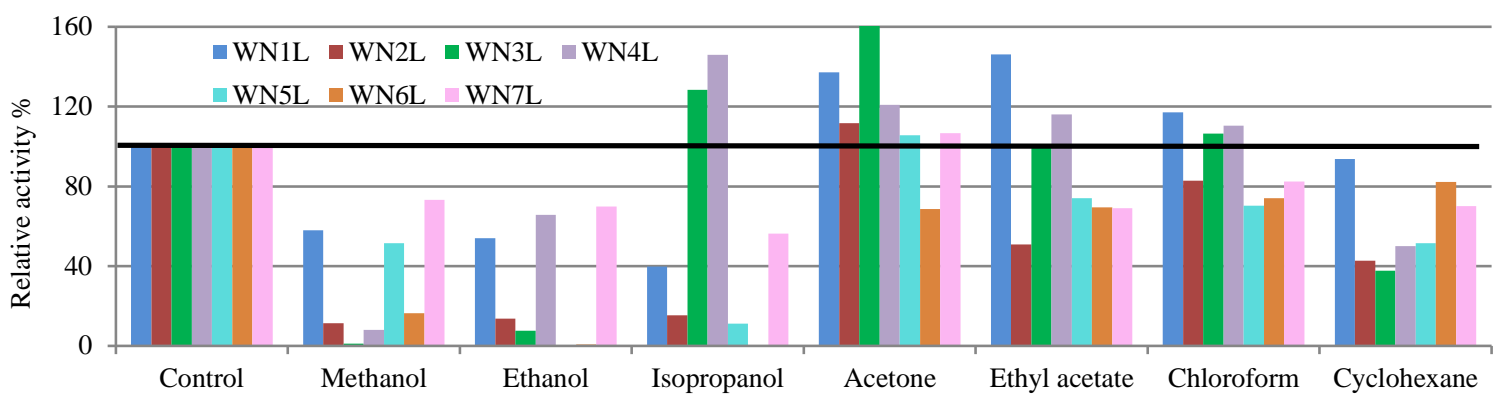

Different solvents

Figure 6 Effect of organic solvents on different lipases

\section{CONCLUSION}

Two clusters of the genus Nocardiopsis were isolated from a soda salt marsh in Wadi El Natrun and molecularly characterized. Lipases from the two clusters shared some characteristic features and differed extensively in many other features. General conserved features appeared in response to $\mathrm{pH}$ (tendency to be highly alkaline, optimum $\mathrm{pH}$ of $9-11$ ) and response against some solvents (mostly activated by acetone and showed better stabilities in water-immiscible organic solvents than water-miscible). Thermal stability and response to many metals and organic solvents showed extensive variability which provided each enzyme its special identity and suitability in particular industrial tasks. Both of general special characteristics and extensive variability in lipases of the genus Nocardiopsis strains of Wadi El Natrun afford them promising extraordinary value in industrial bio-catalysis.

Financial support and sponsorship: This research did not receive any specific grant from funding agencies in the public, commercial, or not-for-profit sectors.

Conflict of interest: The author declares that there are no conflicts of interest.

Acknowledgments: The author thanks the National Research Centre for supporting this work.

\section{REFERENCES}

Atlas, R.M. (1997). Handbook of microbiological media. Boca Raton, Fla: CRC Press

Awad, G.E., Mostafa, H., Danial, E.N., Abdelwahed, N.A., \& Awad, H.M. (2015). Enhanced production of thermostable lipase from Bacillus cereus ASSCRC-P1 in waste frying oil based medium using statistical experimental design. Journal of Applied Pharmaceutical Science, 5(09), 007-015 https://doi.org/10.7324/japs.2015.50902

Aziz, M.M.A., Elgammal, E.W., \& Ghitas, R.G. (2020). Comparative study on modeling by neural networks and response surface methodology for better prediction and optimization of fermentation parameters: Application on thermoalkaline lipase production by Nocardiopsis sp. strain NRC/WN5. Biocatalysis $\begin{array}{lll}\text { and Agricultural } & \text { Biotechnology } & 101619 .\end{array}$ https://doi.org/10.1016/j.bcab.2020.101619

Bennur, T., Kumar, A.R., Zinjarde, S., \& Javdekar, V. (2014). Nocardiopsis species as potential sources of diverse and novel extracellular enzymes. Appl. Microbiol. Biotechnol. 98, 9173-9185. https://doi.org/10.1007/s00253-014-6111 y

Bennur, T., Kumar, A.R., Zinjarde, S., \& Javdekar V. (2015). Nocardiopsis species: Incidence, ecological roles and adaptations. Microbiological Research 174, 33-47. https://doi.org/10.1016/j.micres.2015.03.010

Bhosale, H., Uzma, S., \& Tukaram, K. (2016). Characterization of a Hyperthermostable Alkaline Lipase from Bacillus sonorensis 4R. Enzyme Research 4170684. https://doi.org/10.1155/2016/4170684

Bora, L., \& Bora, M. (2012). Optimization of extracellular thermophilic highly alkaline lipase from thermophilic Bacillus $s p$ isolated from Hotspring of Arunachal Pradesh, India. Brazilian Journal of Microbiology 43(1), 30-42. https://doi.org/10.1590/s1517-83822012000100004

Cao, Y., Zhuang, Y., Yao, C., Wu, B., \& He, B. (2012). Purification and characterization of an organic solvent-stable lipase from Pseudomonas stutzeri LC2-8 and its application for efficient resolution of (R, S)-1-phenylethanol Biochem. Eng. J. 64, 55-60. https://doi.org/10.1016/j.bej.2012.03.004

Castro-Ochoa, L.D., Rodríguez-Gómez, C., Valerio-Alfaro, G., \& Ros, R.O (2005). Screening, purification and characterization of the thermoalkalophilic lipase produced by Bacillus thermoleovorans CCR11. Enzyme and Microbial Technology 37(6), 648-654. https://doi.org/10.1016/j.enzmictec.2005.06.003

Chakraborty, K., \& Raj, R.P. (2008). An extra-cellular alkaline metallolipase from Bacillus licheniformis MTCC 6824: purification and biochemical $\begin{array}{llll}\text { characterization. } & \text { Food chemistry } & 109(4), & 727-736\end{array}$ https://doi.org/10.1016/i.foodchem.2008.01.026

Chakraborty, S., Ghosh, M., Chakraborti, S., Jana, S., Sen, K.K., Kokare, C., \& Zhang, L. (2015). Biosurfactant produced from Actinomycetes nocardiopsis A17:Characterization and its biological evaluation. International Journal of $\begin{array}{lll}\text { Biological } & \text { Macromolecules } & 79,\end{array}$ https://doi.org/10.1016/j.ijbiomac.2015.04.068

Chauhan, M., \& Garlapati, V.K. (2013). Production and Characterization of a Halo-, Solvent-, Thermo-tolerant Alkaline Lipase by Staphylococcus arlettae JPBW-1, Isolated from Rock Salt Mine. Appl. Biochem. Biotechnol. 171, 14291443. https://doi.org/10.1007/s12010-013-0433-6

Daiha, K.d.G., Angeli, R., de Oliveira, S.D., \& Almeida, R.V. (2015). Are Lipases Still Important Biocatalysts? A Study of Scientific Publications and Patents for Technological Forecasting. PLOS ONE 10(6), e0131624. https://doi.org/10.1371/journal.pone.0131624

Dopazo, J. (1994). Estimating errors and confidence intervals for branch lengths in phylogenetic trees by a bootstrap approach. Journal of Molecular Evolution 38 , 300-304. https://doi.org/10.1007/bf00176092

El-Naggar, N.E. (2014). Nocardiopsis synnemasporogenes sp. nov., NEAE-85, a Novel L-Asparaginase Producing Actinomycete Isolated from Soil in Egypt. Journal of Pure and Applied Microbiology 8(6), 4335 - 4343

Gandhi, N.N. (1997). Applications of lipase. Journal of the American Oil Chemists' Society 74(6), 621-634.

Gandhimathi, R., Kiran, G.S., Hema, T.A., Selvin, J., Raviji, T.R., \& Shanmughapriya, S. (2009). Production and characterization of lipopeptide biosurfactant by a sponge-associated marine actinomycetes Nocardiopsis alba MSA10. Bioprocess Biosyst. Eng. 32, 825-835. https://doi.org/10.1007/s00449 009-0309-X

Gohel, V., \& Naseby, D.C. (2007). Thermalstabilization of chitinolytic enzymes of Pantoea dispersa. Biochemical Engineering Journal 35, 150-157. https://doi.org/10.1016/j.bej.2007.01.009

Guerrand, D. (2017). Lipases industrial applications: focus on food and agroindustries. OCL 24(4), D403. https://doi.org/10.1051/ocl/2017031

Hall, T.A. (1999). BioEdit: a user-friendly biological sequence alignment editor and analysis program for Windows 95/98/NT. Nucl. Acids. Symp. Ser. 41, 95 98.

Hamedi, J., Mohammadipanah, F., \& Ventosa, A. (2013). Systematic and biotechnological aspects of halophilic and halotolerant actinomycetes. Extremophiles 17, 1-13. https://doi.org/10.1007/s00792-012-0493-5

Hasan, F., Shah, A.A., \& Hameed, A. (2006). Industrial applications of microbial lipases. Enzyme and Microbial Technology 39 (2), 235-251. https://doi.org/10.1016/j.enzmictec.2005.10.016

Hasan, F., Shah, A.A., \& Hameed, A. (2009). Methods for detection and characterization of lipases: A comprehensive review. Biotechnology Advances 27, 782-798. https://doi.org/10.1016/j.biotechadv.2009.06.001

Hiol, A., Jonzo, M.D., Rugani, N., Druet, D., Sarda, L., \& Comeau, L.C. (2000) Purification and characterization of an extracellular lipase from a thermophilic Rhizopus oryzae strain isolated from palm fruit. Enzyme Microb. Technol. 26 421-430. https://doi.org/10.1016/s0141-0229(99)00173-8

Horikoshi, K. (1999). Alkaliphiles: some applications of their products for biotechnology. Microbiology and molecular biology reviews 63(4), 735-750 https://doi.org/10.1128/mmbr.63.4.735-750.1999

Hozzein, W.N., Li, W.J., Ali, M.I., Hammouda, O., Mousa, A.S., Xu, \& L.H. et al. (2004). Nocardiopsis alkaliphila sp. nov., a novel alkaliphilic actinomycete 
isolated from desert soil in Egypt. Int. J. Syst. Evol. Microbiol. 54, 247-52. https://doi.org/10.1099/ijs.0.02832-0

Hu, J., Cai, W., Wang, C., Du, X., Lin, J., \& Cai, J. (2018). Purification and characterization of alkaline lipase production by Pseudomonas aeruginosa HFE733 and application for biodegradation in food wastewater treatment. Biotechnology \& Biotechnological Equipment 32(3), 583-590. https://doi.org/10.1080/13102818.2018.1446764

Kambourova, M., Kirilova, N., Mandeva, R., \& Derekova, A. (2003). Purification and properties of thermostable lipase from a thermophilic Bacillus stearothermophilus MC 7. J. Mol. Catal. B: Enzyme 22, 307-313. https://doi.org/10.1016/s1381-1177(03)00045-6

Kanlayakrit, W., \& Boonpan, A. (2007). Screening of halophilic lipase-producing bacteria and characterization of enzyme for fish sauce quality improvement. Kasetsart Journal: Natural Science 41, 576-585.

Kato, K., Nakamura, S., Sakugi, T., Kitai, K., Yone, K., Suzuki, J., \& Ichikawa, Y. (1989). Tumor Necrosis Factor and Its Activators for the Treatment of Malignant Tumors, Japanese Patent 1,186,820

Kulkarni, N., \& Gadre, R.V. (2002). Production and properties of an alkaline, thermophilic lipase from Pseudomonas fluorescens NS2W. Journal of Industrial

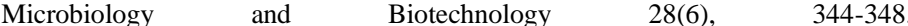
https://doi.org/10.1038/si.jim.7000254

Kumar, V., Bharti, A., Negi, Y.K., Gusain, O., Pandey, P., \& Bisht, G.S. (2012). Screening of actinomycetes from earthworm castings for their antimicrobial activity and industrial enzymes. Braz J Microbiol. 43, 205-214 https://doi.org/10.1590/s1517-83822012000100022

Kumari, A., Mahapatra, P., Kumar, G.V., \& Banerjee, R. (2008). Comparative study of thermostabilty and ester synthesis ability of free and immobilized lipases on cross linked silica gel. Bioprocess and Biosystems Engineering 31(4), 291 298. https://doi.org/10.1007/s00449-007-0160-x

Lajis, A.F.B. (2018). Realm of Thermoalkaline Lipases in Bioprocess Commodities. Journal of lipids 5659683. https://doi.org/10.1155/2018/5659683

Lott, J.A., \& Lu, C.J. (1991). Lipase Isoforms and Amylase Isoenzymes-Assays and Application in the Diagnosis of Acute Pancreatitis. Clin. Chem. 37, 361-368. https://doi.org/10.1093/clinchem/37.3.361

Mauvernay, R.Y., Laboreur, P., \& Labrousse, M. (1970). Lipase Composition and Its Products, United States Patent 3,513,073.

Meena, B., Rajan, L.A., Vinithkumar, N.V., \& Kirubagaran, R. (2013). Novel marine actinobacteria from emerald Andaman and Nicobar Islands: a prospective source for industrial and pharmaceutical byproducts. BMC Microbiol. 13, 145161. https://doi.org/10.1186/1471-2180-13-145

Mitsuiki, S., Sakai, M., Moriyama, Y., Goto, M., \& Furukawa, K. (2002). Purification and Some Properties of a Keratinolytic Enzyme from an Alkaliphilic Nocardiopsis sp. TOA-1. Bioscience, Biotechnology and Biochemistry 66(1), 164-167. https://doi.org/10.1271/bbb.66.164

Ortega, N., de Diego, S., Perez-Mateos, M., \& Busto, M.D. (2004). Kinetic properties and thermal behaviour of polygalacturonase used in fruit juice clarification. Food $\quad$ Chemistry $\quad 88$, 209-217. https://doi.org/10.1016/j.foodchem.2004.01.035

Pera, L.M., Romero, C.M., Baigori, M.D., \& Castro, G.R. (2006). Catalytic Properties of Lipase Extracts from Aspergillus niger. Food Technology \& Biotechnology 44(2), 247-252.

Pogaku, R., Raman, J.K., \& Ravikumar, G. (2012). Evaluation of activation energy and thermodynamic properties of enzyme-catalysed transesterification $\begin{array}{lllll}\text { reactions. Adv Chem Eng Sci. 2, 150-154 } & \end{array}$ https://doi.org/10.4236/aces.2012.21018

Sabry, S.A., Nevine, B.G., Gehan, A.A., Peter, S., Erko, S., \& Reiner, M.K (2004). Nocardiopsis aegyptia sp. nov., isolated from marine sediment. Int. J. Syst. Evol. Microbiol. 54, 453-456. https://doi.org/10.1099/ijs.0.02814-0

Salihu, A., \& Alam, M.Z. (2015). Solvent tolerant lipases: a review. Process Biochemistry 50(1), 86-96. https://doi.org/10.1016/j.procbio.2014.10.019

Sangeetha, R., Arulpandi, I., \& Geetha, A. (2011). Bacterial lipases as potential industrial biocatalysts: An overview. Research Journal of Microbiology 6(1), 1 24. https://doi.org/10.3923/jm.2011.1.24

Schmid, R.D., \& Verger, R. (1998). Lipases: interfacial enzymes with attractive applications. Angewandte Chemie International Edition 37(12), 1608-1633. https://doi.org/10.1002/(sici)1521-3773(19980703)37:12\%3C1608::aidanie1608\%3E3.0.co;2-v

Sharma, R., Chisti, Y., \& Banerjee, U.C. (2001). Production, purification, characterization, and applications of lipases. Biotechnology advances 19(8), 627 662. https://doi.org/10.1016/s0734-9750(01)00086-6

Taher, G.A. (1999). Inland saline lakes of Wadi El-Natrun depression, Egypt International Journal of Salt Lake Research 8, 149-169. https://doi.org/10.1007/bf02442128

Tamura, K., \& Nei, M. (1993). Estimation of the number of nucleotide substitutions in the control region of mitochondrial DNA in humans and chimpanzees. Molecular Biology and Evolution 10, 512-526. https://doi.org/10.1093/oxfordjournals.molbev.a040023

Tamura, K., Stecher, G., Peterson, D., Filipski, A., \& Kumar, S. (2013). MEGA6: Molecular evolutionary genetics analysis version 6.0. Molecular biology and evolution 30(12), 2725-2729. https://doi.org/10.1093/molbev/mst197 